\title{
On the 4-H Study of Positive Youth Development
}

\author{
Stephen F. Hamilton
}

Received: 18 February 2014/ Accepted: 12 March 2014/Published online: 22 March 2014

(C) Springer Science+Business Media New York 2014

\begin{abstract}
The research reported in this issue advances our understanding of the multiple interactive influences on young people's development. The study invokes Relational Developmental Systems Theory to show, among other findings, how the impact of out-of-school time depends on the number and range of different types of activities young people engage in. The study also demonstrates that developmental assets (the $5 \mathrm{Cs}$ ) can co-exist with problem behavior, an important contribution to the positive youth development perspective. Readers will also find in these articles diverse strategies of data analysis and exemplars of research that informs practice as well as theory.
\end{abstract}

\section{Introduction}

This commentary explains that the articles in this special issue are part of a large and impressive body of work that continues to flow from the 4-H Study of Positive Youth Development (PYD). The study results from a noteworthy partnership between the National 4-H Council and the Institute for Applied Research in Youth Development led by Richard M. Lerner at Tufts University. Both the research and the partnership have important implications for understanding and enhancing PYD.

\section{Some Context for the Study}

4-H is the youth component of Cooperative Extension, the institutional manifestation of the mission of all land grant

S. F. Hamilton $(\bowtie)$

Department of Human Development, Cornell University, Ithaca, NY, USA

e-mail: sfh3@cornell.edu universities to share the knowledge of the university with the people of their state. "Cooperative" refers in part to funding, which is provided by the federal government, through the US Department of Agriculture, state, and county governments. Agriculture and homemaking were the traditional domains for Cooperative Extension, which accounts for the association of 4-H with "cows and cookin'." Agriculture continues to be a source of strength, along with what is now known as "family and consumer sciences," especially nutrition. But as the proportion of farm families in the population has shrunk, Cooperative Extension and 4-H have gained prominence in suburban and urban communities where they provide information on gardening, financial management, civic engagement, and other topics informed by university-based researchers.

Based as it is in land grant universities, 4- $\mathrm{H}$ might be expected to generate a great deal of research. And indeed it has. Jan Scholl, a professor at Penn State, has compiled two databases of 4-H research, including graduate studies, with thousands of entries (http://www.libraries.psu.edu/psul/life sciences/agnic/Youth.html). But the need for this compilation demonstrates that most of the research has not entered the scholarly literature. When studies of 4-H have been published, they have usually appeared in journals for practitioners, especially the Journal of Extension and Journal of Youth Development. This observation is not meant to be disparaging. Scholars who hope to see their work acted upon are well advised to communicate directly with practitioners, but publications in such venues are rarely cited in journals for researchers.

Although 4-H has research resources unmatched by any other youth development organization, research has served primarily as a source of content. A 4-H nutrition education program can be counted on to convey the best current knowledge of the subject. But research to guide the structure and functioning of $4-\mathrm{H}$ is scarcer. With the 
exception of the University of Minnesota, whose 4-H program is located in its fine Extension Center for Youth Development, the organization's grounding in youth development research has not been notably stronger than other youth-serving organizations' (described by Bialeschki and Conn 2011).

Along with growing demands from funders for evidence of program effectiveness, this was part of the background for the National 4-H Council raising the funds for rigorous research. The National 4-H Council is a non-profit organization that supports 4-H independently of USDA but in concert. It can accept and disburse donations from corporations and foundations. As a youth development researcher in a land grant university, I am troubled by the fact that the institution most capable of conducting this research is a private university. As an admirer of Richard Lerner's work, I am impressed by the good judgment demonstrated by Don Floyd, CEO (now retired) of the National 4-H Council in selecting Tufts.

The most inspired aspect of the study, though, is that it was designed not only to examine whether and how 4-H participation affects youth development but also to explore a wide range of youth development issues unrelated to 4-H. The result is a unique model of what Stokes (1997) called "use-inspired basic research." At the same time that the study serves as an evaluation of 4-H, it contributes to our understanding of multiple influences on youth development and of the concept itself.

Working regularly with 4-H educators in New York State, I recognize how important it is to practitioners to know that solid research affirms their professional judgment that participants derive many benefits from $4-\mathrm{H}$. As they recruit members and volunteers and try to convince elected officials that their allocation of tax money to $4-\mathrm{H}$ is justified, they can point to good evidence supporting their case (see Lerner et al. 2013).

\section{Research from a Youth Development Perspective}

The series of reports published in scholarly journals, including this issue, advances and illustrates the youth development perspective on young people's growth and development between the onset of puberty and adulthood. Traditionally researchers have looked at components of development, such as cognition, emotions, social relations, and physical maturation, studying each component separately, and then tried to bring the separate components back together. Research in another tradition has focused on understanding known threats to healthy development- - teen parenthood, drug abuse, violence, school failure, and delinquency, for example-examining their incidence, distribution, etiology, and sequelae and defining health as their absence. While both of these approaches continue to be used because they offer valuable insights, the trend over the past few decades has been toward more holistic, ecological conceptions and research designs.

The term, "youth development," embodies this trend. By definition it is a positive orientation that includes all aspects of development. Like positive psychology, it seeks to illuminate how young people thrive rather than how they fail. The 4-H Study of Youth Development has advanced the state of the art in research on youth development by employing an impressive array of analytical procedures with a large, partially longitudinal data set. The theoretical grounding is in Relational Developmental Systems Theory (Overton 2010), which incorporates Bronfenbrenner's (1979) ecological approach to human development. Predictably for a bold venture, it also illustrates some persistent challenges.

\section{Kudos and Questions}

The study's scale is impressive, whether gauged by sample size, number of waves, geographic inclusion, or breadth of measurement. Its cohort-sequential design allows for crosssectional age cohort comparisons as well as longitudinal analyses. Dwindling sample sizes preclude some worthwhile longitudinal analyses and serve as a reminder of how difficult it is to retain a sample over time, especially when relying on institutional (school) support for access to study participants. Readers of this issue can learn a great deal about research design and methods and especially about data analysis techniques that are appropriate to the complex phenomena investigated. The diversity of topics addressed also illustrates how a research team can exploit a rich data set to explore multiple questions.

The value of an ecological approach is illustrated in the article by Agans et al., who report that participation in a range of OST activities is associated with more indicators of PYD. This finding is admittedly suggestive because causation cannot be inferred, a standard problem when trying to study the effects of voluntary participation in programs. But it provides a more nuanced account than previous studies that have found most extra-curricular activities associated with positive indicators for most youth. It points to the potential value of new research into differences among youth who participate in one or one type of activity and those who participate in a range of activities. In addition to demographic differences it would be helpful to know whether youth have differing motives for participation and how the conditions surrounding their participation differ, including parental support and afterschool employment. Schools and communities certainly vary in the number and diversity of the activities they make 
available. A clever design might exploit these differences as a natural experiment to compare youth in locations with more and fewer activity choices.

Thinking in terms of ecology provides a framework for investigating complexity. The article by Bowers et al. is a worthy effort to address a complex set of issues surrounding young people's relations with adults outside their families and especially how parenting profiles interact with those relations and with youth development "outcomes," defined in terms of the 5Cs. This is a critical issue in research on mentoring and mentoring programs. Mentoring programs target youth from single-parent families in the expectation that introducing another caring adult into the lives of such youth will compensate in some ways for the absence of a parent. This assumption is supported by research on resilience finding that the enduring presence of a caring adult, whether parent, other relative, or someone outside the family, is associated with thriving despite disadvantages (Werner and Smith 2001). In this sense, a mentor can substitute for a parent. But Rhodes et al. (2000) found that improvements in young people's perceptions of improved relations with their parents mediate the positive effects of having a mentor, an illustration of the value of Bronfenbrenner's (1979, p. 38) urging to seek indirect as well as direct influences on development. This finding also supports the view that mentors complement rather than replace parents. However, Erickson et al. (2009) found that they do both, marginally enhancing the generally positive achievements of youth with both material and social resources at home but having a very large positive effect on youth with limited resources.

The Bowers et al. article also illustrates how challenging it is to comprehend the kind of complexity that exists outside the laboratory. By incorporating so many variables and attending to their patterns of interaction they generated findings that are difficult to interpret. One can imagine investigators surveying these findings and retreating to the relative simplicity of studying a few variables at a time.

The welcome exploration of parents' influence continues in the work of Callina et al., who set out to examine the influence of parent trust on young people's hopes for the future. Specifically, they looked for evidence that trust in parents predicts hopeful future expectations, which, in turn, produce more contributions to the community. They unexpectedly found that Contribution was highest among youth in the group defined by Moderate Hope and by Trust that followed a U-shaped, high-low-high pattern from early to middle adolescence. This is a reminder of why empirical research is so important; it pushes back against our theories, requiring further work on either theory or measurement, or both.

The definition and operationalization of key constructs might repay further work. The definition of hopeful future expectations adopted sounds a lot like agency; while agency and hope are surely related, they are not identical. The definition of trust as "expectations for warm, supportive, and reliable interactions between themselves and their parents" (pp. 5-6) leaves out other possible aspects of trust such as dependability and reliable adherence to a moral code. The six items from the Search Institute survey used to measure trust are about parent relations, but not explicitly about trusting parents. That said, it is worth knowing that $80 \%$ of the sample was classified as being "High Stable" in both Trust and Hopeful Future Expectations. More research is warranted to understand why that seemingly optimal group did not have the highest Contribution scores.

There is a natural affinity between the youth development perspective and mixed methods. Almost by definition, achieving a holistic understanding entails collecting and analyzing some unquantified data. Hershberg et al. present qualitative findings on thriving and contribution, introduced with a good account of their analytic methods, a challenging task because those methods are typically less precise and less standardized than those employed with quantitative data. Their finding (p. 26) that "while youth may value particular activities as part of their daily lives in adolescence, they do not necessarily consider these activities as an essential part of a thriving future," is reminiscent of what Livson (Livson and Peskin 1980, p. 89) called "genotypic continuity." His illustration was: "a conventionally socialized, very 'nice' adolescent girl is likely to develop into an age-40 woman of considerable depth, strength, and interpersonal attractiveness." The youth whose open-ended responses Hershberg et al. analyzed were able to differentiate between what is important in the present and what will be important in the future, recognizing that in adulthood school and athletics will neither engage them nor give them an identity. An implication is that, as they grow older, some people may draw upon some of the same developmental assets that enabled them to thrive in youth to establish an equivalent adult social position under quite different circumstances.

One of the most important refinements of the youth development perspective to emerge from the 4-H Study of Positive Youth Development is that developmental assets can co-occur with risky behavior. This is the central point of the article by Arbeiter, et al. They note that many proponents of PYD have argued that prevention and treatment programs should recede in favor of creating more opportunities for positive development. However, they found what should have been predictable even by rabid proponents of PYD. Anyone on a college campus realizes that students are no angels, even those whose developmental assets have earned them coveted places at selective colleges. Many of them drink too much. Drug abuse is commonplace. Some cheat. A 
few commit theft and violence. It is not just that youth who are on the right path sometimes engage in risky behavior. Taking risks can be part of the identity development that is the principal developmental task of adolescence, as Silbereisen and Noack (1988) taught us.

Accepting the method of treating both positive and negative behaviors as distinct constructs and looking at the 5Cs separately rather than "as a single, second-order construct" (p. 6) calls attention to a substantive difference between the $5 \mathrm{Cs}$ and the problem behaviors that may exist alongside them. The 5Cs refer to abstract characteristics. The problem behaviors with which they are contrasted are concrete: "delinquency, depressive symptoms, substance use, sexual activity, disordered eating behaviors, and bullying." It is good to be reminded that young people who are basically confident may also be depressed, that they can be caring in general but behave cruelly in a particular situation.

This observation of the coexistence of positive and negative suggests the possible utility of research seeking optimal boundaries and types of risky behavior. Just as Furstenberg et al. (1987) found for young single mothers, there may be types and levels of problem behaviors that are compatible with a positive developmental trajectory but also a point beyond which those behaviors become serious impediments. The difference between recreational drug use and addiction is one example. It immediately suggests the hypothesis that such a "red line" is not absolute but dependent on context. A White middle-class boy who is a B student and gets arrested for malicious mischief is likely to get back on track much more readily than a poor Black boy with equivalent assets who lives in a high-crime neighborhood where arrest is tantamount to conviction and conviction means jail time.

\section{Conclusion}

The team of researchers that produced this issue has done a great service to both scholars and practitioners of youth development. They have provided models of research design and methods that others will profitably adapt and employ. They have reported findings of substantive significance, worthy to be pondered, questioned, and built upon. Their demonstration of how to conceptualize and empirically address issues of importance in both research and practice should encourage others to work at this nexus.

\section{References}

Bialeschki, M. D., \& Conn, M. (2011). Welcome to our world: Bridging youth development research in nonprofit and academic communities. Journal of Research on Adolescence, 21(1), 300-306.

Bronfenbrenner, U. (1979). The ecology of human development: Experiments by nature and design. Cambridge, MA: Harvard University Press.

Erickson, L. D., McDonald, S., \& Elder, G. H., Jr. (2009). Informal mentors and education: Complementary or compensatory resources? Sociology of Education, 82, 344-367.

Furstenberg, F. F., Brooks-Gunn, J., \& Morgan, S. P. (1987). Adolescent mothers in later life. New York: Cambridge University Press.

Lerner, R. M., Lerner, J. V., et al. (2013). The positive development of youth: Comprehensive findings from the 4- $\mathrm{H}$ study of positive youth development. Chevy Chase, MD: National 4-H Council. Retrieved from http://www.4-h.org/about/youth-developmentresearch/positive-youth-development-study/.

Livson, N., \& Peskin, H. (1980). Perspectives on adolescence from longitudinal research. In J. Adelson (Ed.), Handbook of adolescent psychology (pp. 47-98). New York: Wiley.

Overton, W. F. (2010). Life-span development: Concepts and issues. In R. M. Lerner (Ed.), The handbook of lifespan development. Hoboken, NJ: Wiley.

Rhodes, J. E., Grossman, J. B., \& Resch, N. L. (2000). Agents of change: Pathways through which mentoring relationships influence adolescents' academic adjustment. Child Development, 71, $1662-1671$.

Silbereisen, R. K., \& Noack, P. (1988). On the constructive role of problem behavior in adolescence. In N. Bolger, A. Caspi, G. Downey, \& M. Moorehouse (Eds.), Persons in context: Developmental processes (pp. 152-180). New York: Cambridge University Press.

Stokes, D. E. (1997). Pasteur's quadrant: Basic science and technological innovation. Washington, DC: The Brookings Institution.

Werner, E. E., \& Smith, R. S. (2001). Journeys from childhood to midlife: Risk, resilience, and recovery. Ithaca, NY: Cornell University Press.

Stephen F. Hamilton is a Professor of Human Development and Associate Director of the Bronfenbrenner Center for Translational Research at Cornell University. His Ed.D. is from the Harvard Graduate School of Education. He studies youth development and education, especially the transition to adulthood, work-based learning, and mentoring. 